\title{
Organizational and Strategic Alignment for Academic Libraries
}

Brinley Franklin

University of Connecticut, brinley.franklin@uconn.edu

Follow this and additional works at: https://opencommons.uconn.edu/libr_pubs

Part of the Library and Information Science Commons

\section{Recommended Citation}

Franklin, Brinley, "Organizational and Strategic Alignment for Academic Libraries" (2010). Published Works. 22. https://opencommons.uconn.edu/libr_pubs/22 


\title{
Organizational and Strategic Alignment for Academic Libraries
}

\author{
Brinley Franklin
}

Brinley Franklin is Vice Provost, University of Connecticut Libraries. He holds a BA and MLS from the University of Maryland, College Park and an MBA with a concentration in information systems management from The George Washington University in Washington, D.C. He is President of the Association of Research Libraries (ARL) in 2009-2010. He also served as Chair of ARL's Statistics and Assessment Committee for three years and on the ARL Board of Directors for five years. Together with Terry Plum, he developed the MINES for Libraries ${ }^{\circledR}$ protocol used in more than 40 academic libraries during the last five years. Brinley has published numerous articles and several book chapters on library management, financial, and assessment topics and has consulted and made numerous presentations on those subjects.

\section{Introduction}

Research demonstrates that contemporary organizations will not sustain success if they do not act strategically. This is especially true in fields like academic libraries, where both the educational and the information environment are changing rapidly.

Colleges and universities for centuries have had mission statements that in varying degrees consist of educating students, training professionals, engaging in scholarship and research, promoting creative activity, improving healthcare, and providing public service. Increasingly, however, colleges and universities and the libraries that support them must develop strategies to adapt to changing political, social, economic, technological and demographic trends. A college or university's strategic plan needs to reflect its emphases among its various missions and lay out strategies for achieving its goals and objectives related to these missions. Academic libraries must do the same.

Increasingly, modern organizational theory emphasizes that an organization should align its strategies with performance measures. This approach has been popularized by Kaplan and Norton and others since at least the early 1990s. Another method of advancing this alignment is to structure an organization in a way that reflects and reinforces its missions and strategies.

Modern leadership theory calls for a contemporary leadership portfolio that promotes the attainment of an organization's mission and strategic goals and objectives through staff alignment with the strategic plan. Current leadership research also demonstrates that the most successful contemporary leaders lead their organizations in an interactive way. 


\section{The Strategy Focused Organization}

Robert Kaplan and David Norton have co-authored five books that develop the theme of The Strategy-Focused Organization (2001). Best known as the creators of the Balanced Scorecard performance measurement system that was introduced in The Balanced Scorecard: Translating Strategy into Action (1996), Kaplan and Norton have used the Balanced Scorecard and subsequent enhancements since its inception in the early 1990s to help organizations implement their strategies.

The Strategy-Focused Organization provided a framework built on five management principles:

- Translating the strategy to operational terms;

- Aligning the organization to the strategy;

- Making strategy everyone's everyday job;

- Making strategy a continual process; and

- Mobilizing change through executive leadership.

After their third book, Strategy Maps (Kaplan and Norton, 2004), provided a way to align people, processes, technology, and culture to best serve customers and satisfy shareholder objectives, a fourth book, Alignment (Kaplan and Norton, 2006), showed how to align organizational units to a comprehensive strategy. This organizational alignment also enabled an enterprise to synergize its multiple operating units while continually communicating strategy across the organization and aligning individuals' goals and incentives with the strategic plan.

The Execution Premium (Kaplan and Norton, 2008) begins with the premise that managing strategy differs from managing operations. While it is true that a visionary strategy needs to be linked to excellent operational and governance processes, the probability is low that an organization will sustain success solely on the basis of operational improvements. As the authors point out:

Michael Hammer, a visionary leader of reengineering and process management, concurs: "High performance operating processes are necessary but not sufficient for enterprise success." A senior strategic planner at a Fortune 20 company reinforced Hammer's view: You can have the best processes in the world, but if your governance processes don't provide the direction and course correction required to achieve your goals, success is a matter of luck.

Kaplan and Norton conducted a survey in 1996 on the state of strategy execution in companies. They learned that only $40 \%$ of the participating organizations linked their budgets to strategies and only $30 \%$ linked incentive compensation to strategy. In the vast majority of surveyed companies, fewer than 10 percent of the employees reported that they understood their company's strategy. The authors concluded that employees who do not understand their company's strategy cannot possibly link their daily activities to its successful execution (Kaplan and Norton, 2008). 
By 2006, when The Monitor Group asked senior executives about their priorities in a global survey, strategy execution emerged as their number one priority by a wide margin. Yet, the same year, when Balanced Scorecard Research updated Kaplan and Norton's 1996 survey and received responses from 143 performance assessment professionals, it found that 46 percent of their organizations still did not have a formal strategy execution system. Of these sixty-five organizations, 30 percent were performing at roughly the same level as their peer group, 27 percent were performing at a lower level than their peer group, and an additional $16 \%$ were not performing at a sustainable level.

Conversely, of the 78 organizations that did have a formal strategy execution in place, $12 \%$ had demonstrated "breakthrough results" and another $58 \%$ were performing better than their peer group. The strategy execution processes that distinguished the higher performing organizations were identified as:

- Clearly articulating the corporate strategy and measures;

- Managing a limited number of key strategic initiatives;

- Alignment of business units/support units to strategy;

- Communicating the strategy;

- Regularly reviewing the strategy; and

- Regularly updating the strategy to account for changing conditions (Kaplan and Norton, 2008).

\section{Aligning Strategies to Performance}

Francois Bergeron, Louis Raymond, and Suzanne Rivard (2004) note that the concept of strategic alignment derives from a body of work in the organization literature whose fundamental premise is that organizational performance is the consequence of interplay between two or more factors such as strategy, structure, technology, culture, and environment. The classic work, Strategy and Structure, explored in depth the relationship between organizational strategy and organizational structure (Chandler, 1962).

Thomas Plant advocates for the strategic plan to become a living document. He feels

it is important when engaging in a strategic planning exercise to consider how to align the organization's strategic vision with the frontline operations of the organization, so that the vision guides decision making at all levels of the organization (Plant, 2009).

Plant describes four key elements in a holistic strategic planning model at both the strategic and operational levels and aligns the strategic plan, the operational business plan, and the measurement process in this way:

- Develop a strategic vision involving public and staff input; 
- Develop and prioritize strategic goals and initiatives aligned with the vision;

- Develop departmental business plans aligned with the strategic plan; and

- Measure and report results.

Mankins and Steele (2005) report that companies typically realize only about $60 \%$ of their strategies' potential value because of defects and breakdowns in planning and execution. Their firm, Marakon Associates, collaborated with the Economist Intelligence Unit in 2004 to survey senior executives at about 200 companies to see how effective they were in translating their strategies into performance. In the process, they discovered what they call "the strategy to performance gap."

Their prescription for closing the strategy to performance gap is to work on improving both planning and execution simultaneously, creating clear links between them. They identify seven rules to promote this:

- Keep the strategy simple and understandable, to keep everyone headed in the same direction;

- Debate assumptions, not performance measures;

- Use a rigorous framework, and make sure management and organizational units speak a common language;

- Discuss resource deployments early in the planning process;

- Clearly indentify priorities and execution priorities and hold managers accountable for achieving their commitments;

- Continuously monitor performance; and

- Reward and develop execution capabilities.

William Schiemann (1993) describes an organization as an "ecology of forces" such as organizational systems, structure, culture, and capabilities. "When these forces are aligned with the overall strategy, they become powerful supports for change. Nonalignment cripples change; it puts an organization at odds with itself."

\section{Strategic Alignment in the Academic Environment}

There are a few notable examples of aligning strategies to performance in the academic environment. One is The University of Leeds, in the United Kingdom. It articulated a vision to become one of the top 50 universities in the world by 2015 based on their distinctive ability to integrate world-class research, scholarship, and education. Their strategy placed equal importance on research and education, with their differentiating factor being the integration of the two. Its Vice Chancellor stated "the process of truly embedding the university's strategic goals into the working lives of all our staff is our highest priority." In one year, their ranking improved by 41 places, to number 80 , in the THES-QC world university rankings for 2007 (Kaplan and Norton, 2008).

Applying Balanced Scorecard techniques, Leeds developed a strategy map based on four strategic themes: 
- Enhancing its international performance and standards;

- Achieving an influential world-leading research profile;

- Inspiring students to develop their full potential; and

- Enhancing enterprise and knowledge transfer.

Using "Inspiring students to develop their full potential" as an example, four strategic objectives were then developed by various university stakeholders to address that theme:

- Delivering excellent and inspirational learning and teaching;

- Translating excellence in research and scholarship;

- Providing an exceptional student experience; and

- Introducing a comprehensive approach to recruit additional underrepresented and nontraditional students.

Measures, targets, and initiatives were also developed for the strategic objectives as follows:

\begin{tabular}{|l|l|l|}
\hline \multicolumn{1}{|c|}{ Measures } & \multicolumn{1}{|c|}{ Targets } & \multicolumn{1}{c|}{$\begin{array}{c}\text { Initiatives } \\
\text { "Students Really Matter" }\end{array}$} \\
\hline Student satisfaction & $\begin{array}{l}\text { Top quartile of higher } \\
\text { education sector }\end{array}$ & Student satisfaction survey \\
\hline Student/staff ratio & Reduce to 15-1 & $\begin{array}{l}\text { Learning and teaching } \\
\text { process improvement } \\
\text { program }\end{array}$ \\
\hline $\begin{array}{l}\text { Level of demand for } \\
\text { courses }\end{array}$ & $\begin{array}{l}\text { Increase to 8 applications } \\
\text { per place }\end{array}$ & $\begin{array}{l}\text { Student partnership } \\
\text { agreements }\end{array}$ \\
\hline $\begin{array}{l}\text { Average A-level score of } \\
\text { recruited students }\end{array}$ & Increase to 420 & Peer mentoring scheme \\
\hline $\begin{array}{l}\text { Proportion of full-time } \\
\text { undergraduate cohort from } \\
\text { lower socioeconomic } \\
\text { groups }\end{array}$ & Increase to 24\% & Student portal \\
\hline
\end{tabular}

Other universities have aligned their strategies to performance using the Balanced Scorecard, including the University of Edinburgh and the University of California, San Diego, which was inducted into the Balanced Scorecard Hall of Fame in 2003.

\section{Strategic Alignment for Academic Libraries}

The Leeds University Library's strategic plan for 2003-2007 also utilized the Balanced Scorecard approach and followed the Leeds University strategic plan pattern "as far as possible." The Leeds University Library articulates in its mission that it "works in 
partnership with the academic community to support the University's mission." It also states that:

The University of Leeds is characterized by the exceptional breadth and diversity of its activities, a multitude of activities brought together by their capacity to "make a difference". In forming its Strategic Plan for the years up to 2007, the Library has been aware, in turn, of its own potential to have a supportive and creative role in making a difference to all of these activities....

Libraries that have adopted the Balanced Scorecard approach include the National Library of Australia, the University of Hull Libraries, the University of New South Wales, and the University of Virginia Libraries. The Association of Research Libraries is working with Ascendant Strategy Management Group and Johns Hopkins, McMaster, U of Virginia and the $\mathrm{U}$ of Washington to develop or refine library scorecards at those libraries.

Interestingly, although academic libraries exist to support the missions and strategies of their host institutions, unlike the University of Leeds, most academic libraries have not traditionally drafted strategic plans based on their college or university's strategic plan directions.

Library staff members who draft strategic plans often look first at what other peer libraries are doing rather than aligning their libraries strategic plans with their own institution's prevailing visions and strategies. Yet Andrew Dillon, Dean of the School of Information at the University of Texas, writes that:

Academic libraries will survive as long as there are universities.

However, libraries cannot thrive without aligning their workings directly to the core mission of their host institutions (Dillon, 2008).

Academic libraries have always existed to support the principal missions of their college or university. Today, however, advances in information technology, the increased cost of higher education, an aging academic library workforce, and a serious economic downturn have all converged to challenge how libraries engage in their academic support work.

The University of Connecticut Libraries based its most recent strategic plan on the University's academic plan. The Libraries adopted goals that reflected the University's five major themes: Undergraduate Education; Graduate and Professional Education; Research, Scholarship, and Creative Activity; Diversity; and Public Engagement. The Libraries' strategic planning team, based on input from its various stakeholders, wrote a goals statement, strategies, and metrics for each of the five themes in the University's Academic Plan. Illustrative examples follow:

\section{Undergraduate Education}

Goal - Actively support our undergraduates with intellectually challenging and diverse resources, continuous improvement in services, excellent learning 
environments, and opportunities to engage in critical thinking that adhere to information literacy standards.

Strategy - Foster success in undergraduate education by enriching our instruction and outreach efforts to enhance students' information literacy skills.

Metric - Improve scores on library-wide undergraduate-focused qualitative assessments of information literacy.

\section{Graduate and Professional Education}

Goal - Enhance strategic graduate and professional programs through active library liaison engagement and resource support.

Strategy - Promote technology-enhanced individual and collaborative facilities within the Library to promote graduate school interactions and research on all campuses.

Metric - Increase perceived level of service quality for community space for group learning and group study from 6.87 in 2008 to 7.3 in 2014 (relates to LibQUAL+® question LP-5).

\section{Research, Scholarship, and Creative Activity}

Goal - Actively support faculty, student, and staff research, scholarship, and creative endeavors through quality instruction, liaison collaboration, collections, and information access.

Strategy - Enhance access to and awareness of research and publication at UConn.

Metric - Increase the number of items in the DigitalCommons@UConn.edu by $50 \%$, from 4,800 in 2009 to 7,200 by 2014 .

\section{Diversity}

Goal - Ensure an enriched learning and work environment by creating a more inclusive community that recognizes and celebrates individual differences.

Strategy - Strengthen programs that promote cultural competency among faculty, staff, and students.

Metric - Increase the number of diversity-related public programs per year by $50 \%$, from 4 to 6 .

\section{Public Engagement}

Goal - Enhance the contributions of UConn Libraries' staff to the state, nation, and world through public programming and appropriate collaboration with partners in the public and private sectors.

Strategy - Increase the utilization of library staff expertise in the State.

Metric - Increase the number of annual consultancies to public sector organizations by $100 \%$, from 5 in 2009 to 10 in 2014.

Deborah Jakubs (2008) reflects the plight of $21^{\text {st }}$ century academic libraries' when she writes: 
...libraries must continue to prove their value to the university and demonstrate that the very significant investment made in the library is well directed and well spent, an investment not only in our buildings, staff, and collections, but also in the academic success of students and faculty.

\section{Organizational Alignment for Libraries}

An informal survey conducted in 2008 found that, with very few exceptions, academic libraries' organizational structures in the United States were based on functional units with names like: access services; administrative services; collections, instruction, and public services; special collections and archives; technical services; research and instructional services; collection development and management; user services; and reference and instruction. Some functional units had contemporary names like digital library services, scholarly communication, and information technology, but even these were more functional than program or outcomes-based.

Academic libraries in the United States also, for the most part, have maintained a traditional structure headed by a dean, director, or university librarian, a small number of assistant or associate deans, directors, or university librarians (e.g., associate university librarian for digital library services) and a somewhat larger number of functional department heads (e.g., head of systems).

But, as Sarah Pritchard (2008) asserts:

In the digital environment, we still have resources, staff, and facilities that combine in various ways to acquire and provide information. These recombinations challenge traditional definitions of library organization. Library leaders and staff need to do this deconstruction so that stagnation does not set in, and we can incorporate new services and collections while still living within the same budgets and buildings.

Thomas Plant (2009) sets forth that successful implementation of the strategic plan depends on the organizational structure. Similar to academic libraries, Plant notes that many public organizations are bureaucracies that are "centralized, process and status quooriented. He contrasts these traditional characteristics to post-bureaucratic organizations, which are decentralized, change and results-oriented as follows:

\begin{tabular}{|c|c|}
\hline $\begin{array}{l}\text { BUREAUCRATIC } \\
\text { ORGANIZATIONS } \\
\end{array}$ & $\begin{array}{c}\text { POST-BUREAUCRATIC } \\
\text { ORGANIZATIONS }\end{array}$ \\
\hline - Organization centered & - Citizen centered \\
\hline - Position power & - Leadership \\
\hline - Rule centered & - People centered \\
\hline - Independent action & - Collaboration \\
\hline
\end{tabular}




\begin{tabular}{|l|l|l|}
\hline$\bullet$ Status quo oriented & $\bullet$ & Change oriented \\
\hline$\bullet$ Centralization & $\bullet$ & Decentralization \\
\hline$\bullet$ Process oriented & $\bullet$ & Results oriented \\
\hline
\end{tabular}

\section{Organizational and Strategic Alignment for Libraries - The Leadership Challenge}

Aligning an academic library's strategy with performance, coordinating with the university's strategic plan, and adopting a contemporary organizational structure all call for a present-day leadership style. There is an abundance of literature on leadership in modern organizations which generally counsels leaders to move beyond traditional management, sometimes characterized as command and control or outright delegation, toward coaching and counseling. This is especially important in the academic environment, where faculty and librarians are encouraged to act collegially.

Daniel Burnham and David McClelland's early work together in the 1970s identified the successful leader at that time as an institutional leader possessing a strong power orientation. While many of these leaders were "fair, just, and basically democratic in style," they essentially viewed themselves as the "font of power." Burnham reports that the kind of beliefs and attitudes that reflect institutional leaders are:

- "My job is to provide answers to others."

- "People need me."

- "Everyone needs a sense of order and certainty and it is my job to provide it."

Burnham's subsequent related research, reported in his work "Inside the Mind of the World-Class Leader" (2002), indicates that, by the early 1990s, the traditional institutional leader's approach was in many cases not leading to the most successful outcomes. In fact, he found that nearly $60 \%$ of superior performing groups were led by what he now called interactive leaders. While institutional leaders could still achieve some level of success in some organizations, the most outstanding leaders no longer saw themselves as the source of power. Due to many converging social, psychological, technological and economic trends, they had become interactive leaders who derived power from the team, group, or organization they led. Leadership was no longer something that the leader did to others, but rather something they did with others.

Burnham learned through his research that the thought patterns of interactive leaders were characterized by:

- Returning authority to others - identifying the appropriate decision maker, including who wants to be involved and will bring a sense of ownership and pride to the successful completion of the work;

- Mutuality - empathizing in a sincere way and treating others in the organization as equals, not subordinates;

- Paradox and complexity - tolerating uncertainty and displaying patience while the solution is derived rather than making quick decisions to complex problems; and 
- Work focus - being proud of their organizations' work and continually thinking about adjustments as situations change and outcomes evolve (Burnham, 2002).

Another approach to contemporary leadership relevant to the rapidly changing $21^{\text {st }}$ century academic library environment is described by Christensen, Marx, and Stevenson (2006). They assert that to lead change one must first assess the level of agreement in an organization along two critical dimensions, which in combination speak to aligning strategy and performance:

- The extent to which people in the organization agree on what they want - or the extent to which people have the same priorities; and

- The extent to which people agree on cause and effect - or which actions will lead to the desired outcome.

Once each of these dimensions is assessed, Christensen, Marx, and Stevenson identify four tools of cooperation and change:

- Power tools - the use of force and coercion when members of an organization agree on neither the outcomes sought nor the way to get there;

- Management tools - like coordination and standard operating procedures when staff members agree on what course to take, but not where it's ultimately leading them;

- Leadership tools - role modeling and personal charisma are useful when an organization agrees on what it wants, even if consensus is low on how to get there; and

- Culture tools - if members of an organization agree on what they want and how to achieve that goal, they align as a matter of course to head in the same direction. In these organizations, staff members hold a common view of the world and leaders can in many ways allow them to self-manage.

A third view of modern organizational leadership, based on emotional intelligence (EI), was popularized by Daniel Goleman in Working with Emotional Intelligence (1998) and other writings. It has also been studied in the academic library environment by Peter Hernon and Nancy Rossitor (2006) and others.

An interesting EI study of academic research library directors in the western United States by Patricia Kreitz (2009) compiled the most important ideal library director traits, senior management team traits, and shared leadership traits across the four EI domains (self-awareness, self-management, social awareness, and relationship management). Her findings, in rank order for each of the three can be summarized as follows:

\begin{tabular}{|c|c|c|}
\hline $\begin{array}{c}\text { Most Important Ideal } \\
\text { Library Director } \\
\text { Traits }\end{array}$ & $\begin{array}{c}\text { Most Important Ideal } \\
\text { Senior Management } \\
\text { Team Traits }\end{array}$ & $\begin{array}{c}\text { Most Important Shared Ideal } \\
\text { Leadership Traits }\end{array}$ \\
\hline Know where he/she is & Cognitive ability to deal & Ability to listen and delegate \\
\hline
\end{tabular}




\begin{tabular}{|c|c|c|}
\hline $\begin{array}{l}\text { going and taking the } \\
\text { organization }\end{array}$ & $\begin{array}{l}\text { with complex scenarios or } \\
\text { situations }\end{array}$ & \\
\hline $\begin{array}{l}\text { Articulate direction for } \\
\text { library }\end{array}$ & $\begin{array}{l}\text { Ability to understand, } \\
\text { anticipate, and harness } \\
\text { native behaviors or } \\
\text { approaches of staff }\end{array}$ & Having integrity \\
\hline $\begin{array}{l}\text { Able to build a shared } \\
\text { vision and rally others to } \\
\text { it }\end{array}$ & $\begin{array}{l}\text { Lead in a shared decision- } \\
\text { making environment }\end{array}$ & Exercises good judgment \\
\hline $\begin{array}{l}\text { Ability to function in a } \\
\text { political environment }\end{array}$ & $\begin{array}{l}\text { Consensus building in } \\
\text { carrying out strategic } \\
\text { direction }\end{array}$ & Good interpersonal/people skills \\
\hline $\begin{array}{l}\text { Motivate people to } \\
\text { develop and adhere to a } \\
\text { shared vision }\end{array}$ & Accessible to others & Effective in leading change \\
\hline $\begin{array}{l}\text { Ability to gather outside } \\
\text { resources }\end{array}$ & $\begin{array}{l}\text { Expertise in building and } \\
\text { leading teams }\end{array}$ & $\begin{array}{l}\text { Realistic understanding of } \\
\text { oneself; emotions, strengths, } \\
\text { weaknesses, needs, and drives }\end{array}$ \\
\hline & Enabler and facilitator & \\
\hline
\end{tabular}

Kreitz concludes that, in complex organizations, "shared and complementary leadership can work together to create an emotionally intelligent organization that can more effectively achieve the library's vision and goals."

Joseph Matthews (2008) identifies in a different way how library leaders should go beyond the preparation of a mission and vision statement by:

- Stating their strategies publicly;

- Communicating their strategies to every staff member, every time an opportunity presents itself;

- Believe passionately in their strategies;

- Acknowledge that the implementation of their strategies is dependent on all staff members;

- Hold all staff members, especially management, accountable; and

- Systematically measure the progress the organization is making in achieving its vision.

In closing, to achieve success in the rapidly changing information environment, academic libraries must act strategically. Increasingly, academic libraries will be expected to align their strategies with their universities' strategic plans and libraries will need to align strategy to performance. Finally, to be successful, academic library leaders will require a contemporary leadership portfolio that enables them to align staff belief in the library's mission and vision so that library staff members will perform in a way that achieves the library's strategies. 


\section{Acknowledgements}

The author wishes to acknowledge Raynna Bowlby for her support and guidance and Shikha Sharma for her research assistance.

\section{Bibliography}

Bergeron, F et al, (2004) "Ideal Patterns of Strategic Alignment and Business Performance," Information and Management 41: 1003-1020.

Burnham, D. (2002) "Inside the Mind of the World Class Leader" available at: http://www.burnhamrosen.com/articles/Inside_the_Mind.pdf (accessed 6 June, 2008)

Chandler, A.D. (1962) Chapters in the History of the American Industrial Enterprise, Cambridge, MA: MIT Press.

Christensen C., Marx, M., and Stevenson, H. (2006) "The Tools of Cooperation and Change," Harvard Business Review 84(10): 73-80.

Dillon, A. (2008) "Accelerating Learning and Discovery: Refining the Role of Academic Librarians." In No Brief Candle: Reconceiving Research Libraries for the $21^{\text {st }}$ Century, Washington, DC: Council on Library and Information Resources.

Franklin, B. (2009) "Aligning Library Strategy and Structure with the Campus Academic Plan: A Case Study," Journal of Library Administration 49 (5): 495-505.

Goleman, D. (1998) Working with Emotional Intelligence, New York: Bantam.

Hernon, P and Rossiter, N. (2006) "Emotional Intelligence: Which Traits are Most Prized?" College and Research Libraries 67(5): 260-275.

Jakubs, Deborah, (2008) "Out of the Gray Times: Leading Libraries into the Digital Future," Journal of Library Administration 48, (2): 235-248.

Kaplan, R. and Norton, D. (2006) Alignment: Using the Balanced Scorecard to Create Corporate Synergies, Boston, MA: Harvard Business Press.

Kaplan, R. and Norton, D. (1996) The Balanced Scorecard: Translating Strategy into Action Advantage, Boston, MA: Harvard Business Press.

Kaplan, R. and Norton, D. (2008) The Executive Premium: Linking Strategy to Operations for Competitive Advantage, Boston, MA: Harvard Business Press.

Kaplan, R. and Norton, D. (2001) The Strategy-Focused Organization: How Balanced Scorecard Companies Thrive in the New Business Environment, Boston, MA: Harvard Business School Press.

Kaplan, R. and Norton, D. (2004) Strategy Maps: Converting Intangible Assets into Tangible Outcomes, Boston, MA: Harvard Business Press.

Kernaghan, K., Marson, B. and Borins, S. (2000). The New Public Organization. Toronto: Institute of Public Administration of Canada.

Kreitz, P.(2009) "Leadership and Emotional Intelligence: A Study of University Library Directors and Their Senior Management Teams," College and Research Libraries 70(6): 531-554

Leeds University Strategic Plan (2003) available at: http://www.leeds.ac.uk/library/strategic/Strategy.pdf (accessed 6 November2009)

Mankins, Michael C and Steele, Richard, (2005) "Turning Great Strategy into Great Performance," Harvard Business Review 83(7): 64-72.

Matthews, J. (2008) Scorecards for Results: A Guide for Developing a Library Balanced Scorecard. Westport, CT: Libraries Unlimited.

Plant, T. (2009) "Holistic Strategic Planning in the Public Sector" Performance Improvement (2009) 48 (2): 38-43.

Pritchard, S. (2008) "Deconstructing the Library: Reconceptualizing Collections, Spaces and Services." Journal of Library Administration 48(2): 219- 233. 
Schiemann, W. (1993) "Organizational Change Starts with a Strategic Focus." Journal of Business Strategy 14 (1): 43-48. 